\title{
TRADUZIR MME DE STAËL, DIFUSORA DE IDENTIDADES LITERÁRIAS DA ÉPOCA ROMÂNTICA
}

\author{
Narceli Piucco*
}

\begin{abstract}
Resumo: Este artigo $^{1}$ apresenta considerações sobre a autora Mme de Staël, situando-a no contexto da época romântica europeia. Com o intuito de divulgar suas consideráveis ideias literárias, apresenta-se uma revisão de seus escritos sobre a literatura combinada a um breve comentário de algumas de suas obras. Não apenas a literatura, mas as ideias sobre tradução presentes em seus escritos também são aludidas. Segue uma descrição sobre a sua obra Corinne ou l'Italie, e a análise, com base em teorias da tradução e de adaptação, da sua primeira tradução no Brasil, Corina ou a Itália.
\end{abstract}

Palavras-chave: Mme de Staël; Romantismo; Literatura Traduzida.

Segundo a biografia de Diesbach, ${ }^{2}$ Anne-Louise-Germaine Necker, conhecida como Madame de Staël, nasceu em 22 de abril de 1766, em Paris. Ela foi educada em um meio social parisiense repleto de interesses sociais e políticos, pois pertencia a uma família marcante na sociedade da época.

\footnotetext{
* Doutoranda em Estudos da Tradução Pós-graduação em Estudos da Tradução, Universidade Federal de Santa Catarina (UFSC).

${ }^{1}$ Este artigo foi elaborado a partir da pesquisa de mestrado realizada de 2006 a 2008 na área dos Estudos da Tradução, Pós-graduação em Estudos da Tradução, PGET - UFSC.

${ }^{2}$ DIESBACH. Madame de Staël, p. 24.
} 
Desde pequena, ela conviveu com pessoas influentes no meio literário como Diderot, D’Alembert, Mme Geoffrin, Buffon, que frequentavam o salão literário de sua mãe, um dos mais conhecidos de Paris. A celebridade de seu pai permitiu a Mme de Staël uma precoce abertura ao mundo político da aristocracia. Ela estudou inglês, latim, dicção, música, dança, teatro; escrever e ler fazia também parte da sua formação. A combinação de todos esses traços caracterizou sua vida e seu trabalho. Seu gênio natural diferenciou-a do tipo de mulher tradicionalmente admitida pela sociedade da época e, dessa forma, desconcertou seus contemporâneos, o que lhe propiciou alegrias intelectuais e sofrimentos íntimos.

Depois de escrever uma peça de teatro, Sophie ou les sentiments secrets (1786), ela publicou uma obra consagrada ao seu mestre espiritual, Lettres sur le caractère et les écrits de J-J. Rousseau (1788), bem como um ensaio de crítica literária, De la littérature considérée dans ses rapports avec les institutions sociales (1800), no qual ela define uma nova estética literária, sublinhando a importância da paixão e da imaginação. Em seguida, ela escreveu dois romances, Delphine (1802) e Corinne ou l'Italie (1807), que foram considerados pelos autores românticos livros do ideal e do amor. Entretanto, a autora forneceu uma definição do romantismo em seu ensaio De l'Allemagne (1813), obra que foi censurada por conter uma crítica implícita a política de Napoleão. Escreveu também os ensaios De l'influence des passions sur le bonbeur des individus (1796), Réflexion sur le suicide (1812), Du caractère de M. Necker et de sa vie privée (1804), no qual ela faz uma biografia de seu pai, e Dix années d'exil (1821), obra póstuma em que ela critica fortemente Napoleão. As obras de Mme de Staël são ligadas às circunstâncias políticas e às circunstâncias de sua vida e divulgam um conceito de literatura amplo, uma mistura entre o político e o literário. Os acontecimentos históricos também foram imprescindíveis para a biografia de Staël, como a Revolução Francesa, que acabou provocando seu exílio, a 
condição feminina da época, que a limitavam de se expressar como gostaria e a censura de seus livros por Napoleão I, conferiram à Mme de Staël o status de "estrangeira" na França. Ela acreditava que o cosmopolitismo e o diálogo com as outras culturas eram indispensáveis ao progresso das ideias.

Sua relação com literatura e tradução reflete um momento histórico e político em que a França se sobressaia sobre as outras nações da Europa, o grupo de Coppet se opunha à hegemonia do poder imperial. No final do Primeiro Império, ela descreveu em De l'Allemagne o ideal do cosmopolitismo e da livre circulação das ideias que caracterizam o espírito de Coppet:

Les nations doivent se servir de guide les unes aux autres, et toutes auraient tort de se priver des lumières qu'elles peuvent mutuellement se prêter. Il y a quelque chose de très singulier dans la différence d'un peuple à un autre (...) on se trouvera donc bien en tout pays d'accueillir les pensées étrangères ; car, dans ce genre, l'hospitalité fait la fortune de celui qui reçoit. $^{3}$

Sua obra não foi bem aceita na época, pois tinha como objetivo mostrar aos franceses o exemplo de outro povo como modelo cultural. Staël não desejava que os franceses simplesmente imitassem os alemães, mas ela lhes dizia para que eles reencontrassem sua própria riqueza pelo intermediário da Alemanha. A Alemanha representava o ideal estético de uma nova literatura, que Mme de Staël vai chamar de "romântica". Esse diálogo entre as literaturas europeias da época permitirá aos

${ }^{3}$ STAËL. Cuvres complètes de Madame la baronne de Staël-Holstein, t. II, p. 161-162. "As nações devem servir de guia umas as outras; todas estariam enganadas em se privar das luzes que elas podem mutuamente emprestar. Há algo muito singular na diferença de um povo a outro (...) seria ideal em qualquer país acolher os pensamentos estrangeiros, pois a hospitalidade dessa sorte faz a fortuna daquele que recebe." (tradução nossa) 
grupos como o de Coppet de publicar várias obras influentes da época.

A partir de suas obras, principalmente em De la littérature (1800), Staël teorizava que a literatura europeia estava dividida entre norte e sul, com ênfase na cultura, no clima e no povo desses países. Inserida nesse mapa geográfico e cultural, a Itália aparece como um país quente, sensual e afeminado, enquanto a Inglaterra aparece como um país frio, conservador e masculino.

Vechi ${ }^{4}$ afirma que foi pelas mãos de Mme de Staël que o movimento romântico entrou na Itália, em 1816. Assim, o movimento romântico, que unia as preocupações sociais com as doutrinas literárias, representa a renovação política e moral da qual o mesmo era parte integrante. Expressa a nova ordem de ideias e de sentimentos que se elaboravam e se preocupavam mais com o fundo do que com a forma, apesar das aparências.

De acordo com Pardo Bazán, ${ }^{5}$ Mme de Staël encarna a época de transição: chamada a iniciar a sua pátria no romantismo, pertencente por sua filiação ao século XVIII e desse século ela se apoiou no que mais preparou o romantismo, em Rousseau de quem era discípula fervente. Deve-se reconhecer, segundo Bazán, que alguns princípios fundamentais do lirismo moderno se encontram já enunciados no livro De la littérature, e desde 1810 revelou o mundo novo das literaturas do Norte da Europa, o pensamento e a poesia alemã. Pardo Bazán ${ }^{6}$ menciona uma lista de ideias, hoje generalizadas, que pertencem a Mme de Staël: o caráter próprio das literaturas, a reabilitação histórica da Idade Média, o valor de Shakespeare e dos humoristas ingleses, a influência das instituições e dos costumes na literatura, a distinção entre o espírito da sociedade antiga e da moderna, a superioridade

\footnotetext{
${ }^{4}$ VECHI. A estética romântica: textos doutrinários comentados.

${ }^{5}$ PARDO BAZÁN. El lirismo en la poesía francesa, p. 300-302.

${ }^{6}$ PARDO BAZÁN. , p. 72.
} 
das instituições políticas inglesas, o valor psicológico do misticismo, a influência do espírito cavalheiresco sobre o amor e a honra, a instabilidade e a universalidade da poesia, a distinção entre a poesia clássica e a romântica, palavra que por primeira vez escreveu Staël em língua francesa, e a discussão sobre a influência da evolução científica nas artes.

Didier $^{7}$ afirma que a palavra romantismo não designava ainda uma escola literária que ainda não estava constituída, porém uma tendência, uma rede de temas, certa recusa das convenções, a busca da intensidade na expressão. Encontram-se na obra Corinne elementos do classicismo, a variedade de registros se presta à superposição de vários estilos. Os improvisos fortemente marcados pela cultura antiga, as reflexões morais do pai de Oswald que são ligadas ao estilo moralista do Grande século, pertenceriam ao neoclassicismo. Mas Corinne é já uma grande obra romântica e que vai provar seu caráter pioneiro na literatura francesa.

Tieghem $^{8}$ agrupa as ideias particulares de Mme de Staël sobre as tendências românticas dos diferentes gêneros literários. Segundo o autor, ela critica a tragédia clássica fundada na ideia relativa do gosto que representava as paixões e afirma que a tendência do século XIX é a tragédia histórica, marcada pela ação política e pela representação dos caracteres. Para esse novo período, Staël prevê que a comédia terá como matéria os vícios da alma que prejudicam o bem geral; a poesia terá como objeto o enigma do destino humano e o melhor poeta será aquele que tiver a sensibilidade mais viva e representar seu estado íntimo do coração, por meio de versos ou prosa. A crítica literária partirá das obras e extrairá delas as belezas sem se preocupar em saber se elas estão de acordo com as leis da arte. O romance deve ser moral e a sua moral deve partir do estado sentimental dos personagens

${ }^{7}$ DIDIER. Corinne ou l'Italie de Madame de Staël, p. 135.

8 TIEGHEM. Les grandes doctrines littéraires en France, p. 164. 
que farão parte de um mundo próximo do leitor, para que ele sinta as circunstâncias da vida que são evocadas no romance.

Luppé ${ }^{9}$ aborda as ideias literárias de Mme de Staël, situando-a entre a passagem das Luzes ao Romantismo. $\mathrm{O}$ autor a chama de "teórica" devido à importância da escritora na abordagem de teorias literárias em sua obra De la littérature (1800), em que classifica as obras. Ela marca o romance digno desse termo com uma marca tríplice: o "natural", a "moral" e a "pintura dos caracteres" e opõe o "romance moderno" a alguns outros gêneros como o drama e a tragédia, pois, segundo Staël, o romance é feito de dois elementos contraditórios; ele está ligado ao "natural", mas ao mesmo tempo é fruto de um "arranjo", de uma organização. Segundo o autor, ${ }^{10}$ Staël declara que o romance deve "animar a virtude" e que no bom romance, a moral é extraída da narrativa, como um efeito de sua causa. Mme de Staël dá à melancolia, como sentimento literário, sua nobreza. Ela sublinha que a literatura melancólica não nasceu por acaso na Inglaterra, onde reina a liberdade, onde a razão se entrega a ela mesma, pois a melancolia é uma herança das Luzes.

\section{Mme de Staël e a tradução}

Além de abordar a literatura, Mme de Staël descreveu teorias sobre a tradução no seu tratado De l'esprit de la traduction (1820). Ela nomeia a tradução de "comércio intelectual", que é um fator do dinamismo social e deve estar relacionada à "perfeição das letras" e do "espírito humano", pois

\footnotetext{
${ }^{9}$ LUPPÉ. Les idées littéraires de Madame de Staël et l'béritage des lumières (1795-1800).

${ }^{10}$ LUPPÉ. Les idées littéraires de Madame de Staël et l'béritage des lumières (1795-1800), p. 23-37.
} 
Il n'y a pas de plus éminent service à rendre à la littérature, que de transporter d'une langue à l'autre les chefs-d'œuvre de l'esprit humain. (...). D'ailleurs, la circulation des idées est, de tous les genres de commerce, celui dont les avantages sont les plus certains. $^{11}$

A tradução tem a função de fazer uma ponte com o estrangeiro e permite revelar o conhecimento e a identidade nacional e tem papel crucial na disseminação de ideias. De l'esprit des traductions favorece o comércio de ideias, a troca e o diálogo com o estrangeiro. Staël afirma que para favorecer os progressos das Luzes e do pensamento e garantir assim a liberdade, convém não imitar, mas "tomar emprestado", a fim de conhecer e de libertarse de certas formas concebidas que vão banir toda a "verdade natural" da literatura. As transferências culturais facilitam a passagem do singular ao universal no seio da rede de trocas da cultura do cosmopolitismo. Na sua visão de perfeição, a tradução contribui ao desenvolvimento das letras, pelo conhecimento de outras culturas europeias, e ao renascimento das fontes de inspiração graças à mediação do estrangeiro. Dessa forma, Staël anuncia uma nova sensibilidade estética em tradução cuja condição essencial é o espírito de liberdade; é conhecendo a riqueza de outros povos que a literatura nacional pode se renovar e a prática de tradução permite que uma nação se torne ela mesma.

Ela denuncia, na obra citada, as traduções francesas chamadas belles infidèles, pois elas não forneceriam novas ideias ao gênio criador, ou seja, nelas a identidade da literatura

\footnotetext{
${ }^{11}$ STAËL. De l'esprit des traductions (1820-1821), p. 140-151. "Não há mais eminente serviço que se possa prestar à literatura do que transportar de uma língua para outra as obras-primas do espírito humano. (...) Alias, a circulação das idéias é, de todos os tipos de comércio, o que apresenta as mais seguras vantagens." (tradução de Marie Hélène C. Torres em: FÁVERI; TORRES. Clássicos da teoria da tradução.)
} 
estrangeira se perderia. Para ela, traduzir seria transpor o pensamento estrangeiro de modo a manter o sentido singular, a tonalidade e a energia. A obra estrangeira não deve ser considerada como bárbara, pois seria reconhecida na sua diferença e originalidade.

\section{A obra Corinne ou l'Italie e a tradução no Brasil}

Corinne ou l'Italie, obra dividida em XX livros, subdivididos de 03 a 05 capítulos, escrita em 1805, foi publicada em Paris em 1807 pela Editora Nicolle. O título Corinne ressalta a característica de romance e o subtítulo L'Italie remete ao guia de viagem ou a um tratado sobre a Itália, representando a arte de Staël em unir os dois temas em um só livro. A obra foi traduzida para o inglês Corinne, or Italy e para o alemão, Corinna oder Italien em 1807, no mesmo ano de sua primeira publicação em francês e para o italiano no ano seguinte 1808 La Corinna ossia l'Italia e teve 14 edições entre 1807 e 1810.

O romance tem como paisagem principal a Itália e a passagem da personagem pelas cidades de Roma, Veneza, Florença. A obra Corinne faz a ligação dos elementos do romance aos de uma narração de viagem, situando a Itália e seus costumes, sua literatura e arte. $\mathrm{O}$ itinerário descrito ao longo do livro se inicia com a vinda de Oswald da Escócia e continua com a passagem pela Alemanha, Innsbruck, quando ele chega à Ancona e vai a Roma, onde encontra Corinne.

A questão da linguagem dos personagens é intrigante, pois o narrador onisciente utiliza o francês para relatar as falas que pertencem a domínios linguísticos diferentes. Sabe-se que o Conde de Erfeuil é o único que se recusa a falar em outras línguas, mas apenas em francês. Corinne fala italiano, inglês e francês, e a perfeição do seu sotaque inglês constitui um enigma em uma parte do romance. Mas Staël não deixa claro, de modo geral, em qual língua são feitos os diálogos entre Oswald e Corinne. Ao contrário, 
há uma diferença entre dois tipos de diálogos, os diálogos de ideias e aqueles ligados diretamente à intriga. Quando a descrição da Itália não é feita pela voz de Corinne, é o narrador quem toma o seu lugar de guia, esse narrador onisciente que tende a se aproximar do ponto de vista de Corinne. Por meio da voz do narrador, o leitor descobre, pouco a pouco, os personagens, assim como pela variedade de vozes dos outros personagens. Didier ${ }^{12}$ comenta sobre a voz narrativa adotada por Mme de Staël no romance. Ao contrário dos romancistas de seu tempo, ela preferiu não apresentar esse narrador e a ausência de texto prefacial sublinha esse apagamento. $O$ único paratexto que se tem são as notas do autor, de dois tipos, as notas de rodapé e de fim de volume, mas essas notas não podem pertencer a um narrador. Esse narrador intervém na narrativa, já que a sua voz é presente de forma sutil no romance.

Estão inclusos na obra as composições e os poemas em prosa improvisados que essas paisagens e os poetas antigos como Ovídio, Virgilio e também contemporâneo, como Goethe, inspiraram a escritora Staël, manifestando seu lirismo pessoal romântico. Os dois improvisos são escritos em um estilo particular que evoca o lirismo da poesia italiana. O único poema não improvisado pela personagem Corinne é seu último canto, em que faz seu adeus à vida, no final do romance.

Uma forma de expressar a palavra dos personagens são as cartas. Didier ${ }^{13}$ afirma que a escolha do romance na terceira pessoa pode parecer simbólica da passagem de um século a outro, pois o romance por cartas convinha ao século XVIII. Contudo, o romance na terceira pessoa não exclui o uso da carta que é feito por Corinne para se dirigir a Oswald e por Oswald a Corinne quando ele estava na Escócia e também a Castel-Forte quando Corinne retorna à Itália.

${ }^{12}$ DIDIER. Corinne ou l'Italie de Madame de Staël, p. 83.

${ }^{13}$ DIDIER. Corinne ou l'Italie de Madame de Staël, p. 79. 
Mesmo transpondo a realidade italiana ao seu livro, ela colocou também muito dela mesma e de sua vida. O itinerário da viagem à Itália, foi, em parte, o de Staël de dezembro à junho de 1804-1805. Didier ${ }^{14}$ afirma que os itinerários da personagem e da autora não são exatamente os mesmos, mas as impressões anotadas nos seus carnets de viagem foram reutilizadas no romance.

Didier $^{15}$ comenta a recepção da obra Corinne em 1807. Segundo a autora, o sucesso foi imenso e a importância da obra levou a maior parte dos jornais a escrever artigos. A obra foi melhor compreendida na Inglaterra e na Alemanha. Na França, as críticas vão reagir com os códigos que são aqueles de um classicismo findante; os artigos dos jornais oficiais são hostis e os dos jornais de oposição são favoráveis. A compreensão de Corinne será mais profunda alguns anos mais tarde, justamente porque as ideias, os temas, a estética inaugurados por Mme de Staël foram assimilados pelo público e pelos escritores da nova geração.

Com o objetivo de buscar traduções em português, feitas no Brasil, da obra Corinne ou l'Italie de Mme de Staël, foi feita uma pesquisa detalhada em bibliotecas e na internet, sem sucesso. Uma tradução foi encontrada mais tarde por coincidência em um site de sebo, na seção "escritores alemães", onde o nome da escritora foi registrado com grafia incorreta Mme. de STAËLHolestein, sendo que o nome correto é Mme de Staël-Holstein. O título Corinne ou l'Italie foi traduzido como Corina ou a Itália. A obra pertence às Edições Cultura, série "Novelas Universais" e é composta de dois tomos. Sabe-se que Corina ou a Itália foi revista por Oliveira Ribeiro Neto e publicada em 1945, mas não se tem nenhuma informação a respeito do tradutor e por isso não é possível saber se é uma tradução ou uma reedição de tradução. Dessa forma, não existem dados suficientes sobre o tradutor que

\footnotetext{
${ }^{14}$ DIDIER. Corinne ou l'Italie de Madame de Staël, p. 13.

${ }^{15}$ DIDIER. Corinne ou l'Italie de Madame de Staël, p. 136.
} 
possibilitam determinar a sua "posição tradutiva", tampouco o seu "horizonte tradutivo", definidos por Berman em Pour une critique des traductions: Jonb Donne (1995), em que apresenta um projeto analítico possível ao estudo de traduções. Consequentemente, na análise da tradução, a posição tradutiva foi delineada a partir do texto em si.

Na descrição da obra traduzida, pode-se sublinhar ainda que não há nenhum prefácio, posfácio ou algum paratexto sobre a autora e a obra. Apenas no verso da capa há algumas menções críticas da Academia Brasileira de Letras e de escritores como Afrânio Peixoto, entre outros. A tradução não apresenta notas da edição original, apenas as notas da autora e não acrescenta notas próprias do tradutor. As notas da autora são indicadas por um asterisco no rodapé da página. Não há nenhuma informação a respeito dessas notas, não se sabe ao certo, ao ler o texto, qual a sua procedência.

A tradução é dividida em livros e capítulos, como a divisão feita no original. A divisão dos parágrafos na tradução foi, em geral, reproduzida da mesma forma que no original, mas encontram-se parágrafos divididos de maneira diversa da que consta no original.

Foi possível observar na análise da tradução que não há discrepâncias com o texto original, possivelmente utilizado pelo tradutor da obra e aquele usado para este trabalho de análise, Corinne ou l'Italie (1985, baseado na edição. de 1807). No entanto, a primeira tradução não apresenta nenhum paratexto com informações sobre a edição do original que foi utilizada, se foi a edição de 1820 das CEuvres complètes, corrigida pelo filho da autora August de Staël, ou a edição de 1807, corrigida pela autora.

No que diz respeito à censura da década de 1940, época em que a tradução foi editada no Brasil, não foram observadas alterações, supressões ou aspectos que indicassem algum tipo de censura. Conforme Lia Wyler, ${ }^{16}$ tudo que se refere à Era Vargas

\footnotetext{
${ }^{16}$ WYLER. Que censura?
} 
(1930-53), marco fundador da tradução industrial brasileira, inclusive a censura e suas consequências, tem grande pertinência para se entender o que foi, quais transformações sofreu e o que é hoje a tradução em nosso país.

Um dos objetivos desta análise também foi verificar prováveis processos de adaptação na tradução, pois a adaptação parte de operações tradutivas ligadas ao original, mas sem considerar que todas as operações utilizadas na tradução são adaptações. Dessa forma, buscou-se avaliar o conjunto e a amplitude dos "afastamentos", considerando a distância temporal e sociolinguística da tradução.

Gambier ${ }^{17}$ afirma que os limites entre a tradução e a adaptação não são estabelecidos claramente, o que se tem como ideia geral é que a adaptação está ligada a certos tipos de textos (teatro, publicidade, por exemplo) e implica certa liberdade do tradutor, a quem seriam permitidas modificações, ajustes, acréscimos, omissões no texto de partida para melhor o dobrar aos receptores, aos seus hábitos e suas normas de recepção. Implicitamente, a "tradução" se definiria como um esforço literal, uma mimeses do original.

Adaptação, segundo Bastin, ${ }^{18}$ pode ser entendida como um conjunto de operações tradutivas que resultam em um texto não aceito como tradução, mas reconhecido como representante de um texto fonte com aproximadamente a mesma extensão. $\mathrm{O}$ conceito de adaptação requer a recognição de tradução como não adaptação. De acordo com a amplitude desse afastamento, a tradução será adaptação, mas é difícil de imaginar que nenhuma tradução tenha atingido uma distância temporal, espacial ou sociolinguística considerável.

\footnotetext{
${ }^{17}$ GAMBIER. Adaptation: une ambiguité à interroger, p. 421.

${ }^{18}$ BASTIN. Adaptation, p. 5.
} 
Verificaram-se os prováveis processos de adaptação na primeira tradução, a partir dos conceitos referenciados por Bastin, ${ }^{19}$ mas sem considerar que todas as operações utilizadas na tradução são adaptações. A análise mostrou que a maioria dos processos de adaptação encontrados na primeira tradução acontece por escolha do tradutor, em função da construção do texto e da estilística própria, mas não em função da diferença das línguas, devido à semelhança entre o francês e o português, pois há casos onde algo que estava sugerido ou subentendido no texto fonte é abertamente expresso na tradução.

A partir da leitura, pode-se perceber que o tradutor utiliza determinadas escolhas na primeira tradução em função do leitor e da época em que a obra foi traduzida. Isso se explica pelas "deformações" descritas por Berman: ${ }^{20}$ a "clarificação" e o "enobrecimento", encontradas ao longo da primeira tradução. De acordo com Klaudi, ${ }^{21} \mathrm{em}$ artigo para a Routledge Encyclopedia of Translation Studies, "explicitação" é a técnica de tornar explícito no texto alvo a informação que está implícita no texto fonte. As estratégias de explicitação são geralmente discutidas juntamente com as estratégias de adição e omissão. Pode-se considerar que a "explicitação", definida por Klaudi, ${ }^{22}$ e a "expansão" descrita por Bastin $^{23}$ como processos de adaptação de mesma ordem. No ponto de vista da autora, o termo explicitação deveria ser reservado para adições que não podem ser explicadas pela diferenças de estrutura, estilística ou retórica entre as duas línguas. A primeira tradução explicita os contextos e, por vezes, interpreta-os ao leitor.

Assim, foram percebidos exemplos de "clarificação" na primeira tradução, o que mostra que ela tende a adaptar o original,

\footnotetext{
${ }^{19}$ BASTIN. Adaptation.

${ }^{20}$ BERMAN. A tradução e a letra, ou, O albergue do longínquo, p.50-52.

${ }^{21}$ KLAUDY. Explicitation, p. 80.

${ }^{22}$ KLAUDY. Explicitation.

${ }^{23}$ BASTIN. Adaptation.
} 
inscrevendo na tradução uma individualidade estilística. Outra tendência descrita por Berman, ${ }^{24}$ o ennoblissement, consiste no embelezamento do discurso por meio de frases elegantes, utilizando o original como matéria-prima. Encontrou-se na primeira tradução exemplos de "embelezamento" do original, que geram a "expansão" e adaptação ao modo do tradutor.

Outro exemplo de processo de adaptação é a "omissão ou redução de trechos do original". ${ }^{25}$ Encontraram-se vários outros exemplos de omissão de alguns trechos na primeira tradução. No livro II, foi encontrada a omissão de um parágrafo inteiro.

\section{Considerações finais}

Algumas formas de adaptação foram observadas na primeira tradução Corina ou a Itália, por meio dos processos de adaptação como "clarificação", "omissão", "embelezamento", que tem como consequência a "expansão", e do direcionamento ao leitor e à época. Contudo, o estilo do discurso observado na tradução para o português é coerente, mantém certa unidade.

A obra Corinne ou l'Italie tem apenas uma primeira tradução no Brasil, fora do mercado editorial, que é considerada uma tradução-introdução. Assim, toda primeira tradução pede uma retradução, que tende a se aproximar do original, pois a retradução permite dar continuidade à dimensão sociocultural e expandir a dimensão histórica da obra na literatura receptora, pois ela é a transformação do texto traduzido através do tempo. Como afirma Berman, ${ }^{26}$ de fato, é a obra que muda e que adquire novas perspectivas e representações por meio das traduções e

\footnotetext{
${ }^{24}$ BERMAN. A tradução e a letra, ou, O albergue do longínquo, p. 57.

${ }^{25}$ BASTIN. Adaptation, p. 5-8.

${ }^{26}$ BERMAN. A tradução e a letra, ou, O albergue do longínquo.
} 
retraduções. A retradução também serve de fonte aos estudos da tradução, à crítica de tradução e aos estudos literários.

Milton e Torres, na apresentação do Cadernos de Tradução, n. 11, Tradução, Retradução e Adaptação, mencionam algumas razões para retradução: ela pode ser um suplemento para as seguintes traduções e assim compreender o "mosaico" do original, uma estratégia comercial que oferece um novo produto, supostamente "mais próximo do original" e "mais acurado" do que todos os outros, um desejo para a emulação pessoal ou uma produção específica em um certo lugar e tempo.

Corinne ou l'Italie está sendo retraduzida, a partir do projeto de pesquisa de doutorado em Estudos da Tradução. Devido a pesquisa já efetuada no Mestrado, o estudo da escritora Mme de Staël e suas obras, e mais especificamente Corinne ou l'Italie, objetiva-se desenvolver uma pesquisa mais abrangente em tradução comentada, por meio da tradução integral da obra escolhida.

As obras de Mme de Staël são pouco conhecidas e estudadas no Brasil. Uma escritora da sua importância para a literatura, não só francesa, como universal, é merecedora de um espaço de estudo na área da literatura e dos Estudos da Tradução. A apresentação de sua obra por meio das traduções no Brasil ainda é muito restrita, devido à inexistência de obras suas traduzidas e em circulação, ao contrário da Inglaterra, Alemanha, Itália, e mesmo Espanha, que possuem um número considerável de traduções das obras de Staël.

Dessa forma, por se tratar de uma obra influente da literatura francesa e que ainda não possui tradução atual para o português no Brasil, também por ser considerada uma traduçãointrodução, com características adaptadoras, justifica-se a retradução da obra Corinne ou L'Italie para o projeto de doutorado em tradução comentada. 
Résumé: Cet article présente des considérations sur l'auteur Madame de Staël, en le plaçant dans le contexte de l'époque romantique en Europe. En vue de divulguer ses importantes idées littéraires, on présente ici une révision de ses écrits sur la littérature, ainsi qu'un bref commentaire sur certaines de ses ouvres. Non seulement la littérature, mais ses écrits sur la traduction sont également évoqués. Ensuite, il y a une description de son ouvre Corinne ou l'Italie et une analyse basée sur des théories de la traduction et de l'adaptation de la première traduction au Brésil, Corina ou a Itália.

Mots clés: Mme de Staël; Romantisme; litterature traduite.

\section{REFERENCIAS}

BASTIN, Georges L. Adaptation. In: ROUTLEDGE Encyclopedia of Translation Studies. New York: Routledge, 1998. p. 5-8.

BERMAN, Antoine. A tradução e a letra, ou, O albergue do longínquo. Trad. Marie-Hélène C. Torres, Mauri Furlan e Andréia Guerini. Rio de Janeiro: 7Letras/PGET, 2007.

BERMAN, Antoine. Esquisse d'une méthode. In: Pour une critique des traductions: John Donne. Paris: Gallimard, 1995. p. 64-97. DIDIER, Béatrice. Corinne ou l'Italie de Madame de Staël. Commente. Paris: Gallimard, 1999.

DIESBACH, Ghislain de (1983). Madame de Staël. Paris: Perrin, 2008. FÁVERI, Cláudia Borges de; TORRES, Marie Hélène C. (Org.). Clássicos da teoria da tradução. Florianópolis: UFSC, Núcleo de Tradução, 2004. p. 140-151. v. 2.

GAMBIER, Yves. Adaptation: une ambiguité à interroger. Meta, 37 (3), 1992, p. 413-417. Disponível em: <http: www.erudit.org/revue/meta/ 1992/v37/h3/002802ar.html http://www.erudit.org/revue/meta/1994/ v39/n3/002799ar.pdf > . Acesso em: out. 2009. 
KLAUDY, Kinga. Explicitation. In: ROUTLEDGE Encyclopedia of Translation Studies. New York: Routledge, 1998. p. 80-84.

LUPPÉ, Robert de. Les idées littéraires de Madame de Staël et l'héritage des lumières (1795-1800). Paris: Librairie Philosophique J.Vrin, 1969.

PARDO BAZÁN, Emilia, Condesa de. (1851-1921). El lirismo en la poesía francesa. Alicante: Biblioteca Virtual Miguel de Cervantes, 2002. Edição digital baseada na de Madrid, Editorial Pueyo, [s.d]. Disponível em: http://www.cervantesvirtual.com/servlet/SirveObras/081484097 33581528654480/index.htm.Acesso em: 25 ago. 2009.

PARDO BAZÁN, Emilia, Condesa de. (1851-1921). La literatura francesa moderna. El Romanticismo. Alicante: Biblioteca Virtual Miguel de Cervantes, 2002. Edição digital a partir da 2. ed. de Obras completas de Emilia Pardo Bazán. v. 37, Madrid: V. Prieto y Cía, 1911. Disponível em: <http://www.cervantesvirtual.com/servlet/SirveObras/77145605 320667595510657/p0000001.htm\#I_3_>. Acesso em: 26 ago. 2009.

STAËL, Mme de. Corinne ou l'Italie. Édition de Simone Balayé. Paris: Gallimard,1985 (Folio Classique).

STAËL, Mme de. De la littérature. Paris: Flamarion, 1991.

STAËL, Mme de. De l'esprit des traductions (1820-1821). Trad. Marie Hélène C. Torres. In: FÁVERI, Cláudia Borges de; TORRES, Marie Hélène C. (Org.). Clássicos da teoria da tradução. Florianópolis: UFSC, Núcleo de Tradução, 2004. p. 140-151. v. 2.

STAËL-HOLSTEIN, Madame la baronne de. CEuvres complètes de Madame la baronne de Staël-Holstein. Taylor Institution, 1954. Tome I. Disponível em: <http://books.google.com>.

TIEGHEM, Philippe Van. Les grandes doctrines littéraires en France. $1^{\text {ère }}$ ed. 1946, 1990, Paris: Presses Universitaires de France.

TORRES, Marie Hélène C. Panorama du marché éditorial français: les traductions, retraductions, réeditions et adaptations françaises de la littérature Brésiliènne. In: MILTON, John; TORRES, Marie-Hélène C. (Org.). Cadernos de Tradução. Florianópolis: Pós-graduação em Estudos da Tradução, n. 11, 2003, p. 299-250. 
VECHI, Carlos Alberto; GOMES, Álvaro Cardoso. A estética romântica: textos doutrinários comentados. São Paulo: Atlas, 1992.

WYLER, Lia. Que censura? Revista de Documentação de Estudos em Lingüística Teórica e Aplicada, v. 19, Especial Trabalhos de Tradução, 2003.

Recebido para publicação em 31 de janeiro de 2010 Aprovado em 29 de junho de 2010 